\title{
Relations between Mothers and Adolescent Daughters in the Israeli Bedouin Society Characterized by Education of Traditional Values
}

\author{
Muhammad Suwaed ${ }^{1} \&$ Faten Swaid ${ }^{2}$ \\ ${ }^{1}$ Department of Political and Social Sciences, Western Galilee and Kinneret College, Israel \\ ${ }^{2}$ Educational Counselor, Kaabiya Tabash, Israel \\ Correspondence: Muhammad Suwaed, P.O.B. 73, 30055 Rama, Israel. Tel: 972-507-362-425. E-mail: \\ suwaedm@hotmail.com
}

Received: December 8, 2014 Accepted: January 9, 2015 Online Published: April 28, 2015

doi:10.5539/ies.v8n5p75

URL: http://dx.doi.org/10.5539/ies.v8n5p75

\begin{abstract}
In recent decades, the Bedouin population in Galilee, in Northern Israel, experienced significant multifaceted changes. Exposure to other cultures and other social components, with which this population had very limited interaction in the past, had affected its norms and behavior patterns and caused adaption of manners and values that had not been tolerated in the past. As school in Israel is compulsory and local high school served various segments of the society, all Arab minority children faced a different reality from the one their parents had to cope with. This fast-changing modern reality affected the adolescents and often led to tensions and difficulties between youngsters and parents in general, and daughters and mothers in particular. The following is a summary of a qualitative study conducted among selected number of working educated mothers in this particular sector. The research method was an open semi structured interviews and one on one conversations. All interactions with the researcher had been conducted in Arabic, recorded and translated into English.
\end{abstract}

Keywords: Bedouin, education, tradition, women, adolescent

\section{Introduction}

Parents can be involved in the education of their children in various ways. The literature indicates that there is no general agreement regarding the precise meaning of this term. According to Coleman and Churchill (1997), various scholars and educators attribute various interpretations to this term. Kelly-Laine (1998) and Leichter (1985), point out two main types of parental involvement: collective involvement, focusing on the communityregional-national aspects and personal involvement of parents in the education of their children. Most scholars agree that it is impossible to set rules regarding the type, and the measure of parental involvement (F. Garcia \& E. Garcia, 2000).

So far, very few studies investigated the differences in attitude and scope of intervention between parents of western society and parents of traditional society in transition. According to Chao (2001) and Fung (1999), who investigated differences between mothers in the USA and mothers in China, most of the differences found reflect the cultural differences and approach.

This study appears to be the first of its kind that was conducted in a society that undergoes a lifestyle transition: it reflects the approach and perceptions of mothers who are either first or second generation of women to attending an educational framework. They have their own pace of adapting to modernism, and the intricate situation is reflected by their embracement of education on one hand, and clinging to tradition on the other.

Regardless of the changes that have occurred in the Bedouin society in the recent half-century, as also in the Arabic society in general, this society still prefers collective orientation rather than individual orientation, in its social, family, and inter-family relations. Dependency among members of the nuclear family and within the extended family is very important and is reflected by general and financial support, assistance in child-rearing, and the like (Al Haj, 1987; Baraket, 1985).

According to Dwairy (2006), and others, the Bedouins in Israel comprise a sub-group within the Israeli Arabic minority; although it is an inseparable part of the inclusive Israeli-Arab society, it is distinguished from the other sub-groups within the Israeli society by its unique culture, history, social and political characteristics. 
The Bedouin society tends to be a collective authoritative society; the family and the clan are more important than the individual, therefore, socialization tends to be authoritative, encouraging dependency and conformity rather than independence and freedom of choice. Thus, the individualization process of Arab youngsters does not lead to self-consolidation and independent personality. In such a patriarchal society, the father is the dominant figure, whose authority is respected by the others, who also accept his legitimate right to determine and make decisions in many aspects of their life (Al-Krenawi, 2000).

In the Bedouin society, the status of the individual changes according to his/her age and gender, as there are pre-set rules and regulations at all the organizational levels. The female status is lower than that of the male, but that also changes during the cycle of her life, and the roles she has to fulfill also change accordingly (Hassan, 1999).

According to Abu-Asbah (2005), the social status of the Bedouin woman is negatively affected two different factors: the first is the fact that as Arab women they belong to the ethnic minority and the second one is due to the fact that that they live in a traditional patriarchal society. For Bedouin women, the second factor has significantly more importance, as they are part of a conservative sub-group of the general Israeli Arab culture. Thus, the mother has to educate her daughter in compliance with traditional values, which also determine that both of them are patronized by the man of the house.

This article will examine issues and patterns of maternal intervention in the education of their adolescent daughters and the influence of the cultural and traditional background upon this maternal intervention among Bedouin mothers in northern Israel. It will present difficulties and conflicts that occur between daughters struggling to adopt different behavioral patterns and the mothers who sternly insist that they respect tradition and behave according the conformed accepted behaviors.

"In the patriarchal hierarchal structure of the Bedouin society, the mother is responsible for the education of their daughters, so in order to keep her own status in the family; she must prevent any negative behavior that would threaten her traditional position that might lead to negative consequences" (Kohen, 1999).

\section{Background}

\subsection{Bedouin Society: General Background}

The origin of Bedouins is from the ethnic groups of nomads living in tents, who were traditionally associated with grazing flocks of animals and camels. Today, the Bedouins in Israel are no longer nomads; there are no vast empty spaces allowing nomads to roam, so they had to adapt and settle. Today, most Israeli Bedouins live in rural settlements with a number of urban centers. However, a few thousand Bedouins live in unrecognized settlements, due to the fact that they built settlements without government permission and/or approval. The Israeli Bedouins a population is approximately 250,000 concentrated mostly in two geographical areas sub-divided into distinct tribes and clans. About 100,000 Bedouins live in Galilee in Northern Israel, and approximately 150,000 live in the Negev, in southern Israel where in addition to rural settlements, they have a number of urban centers. In addition to the above, few relatively small Bedouin communities settled near a number of Arabic villages.

The transformation process and the transition from a nomadic lifestyle to life in permanent locations affect the Bedouin society life and altered some of their views perception and priorities which are also affected by the Israeli society and its values, and lifestyle.

"This process led to growing uncertainty, tensions, and worries about the future. Following is a list of the most prominent changes that occurred within the Bedouin society due to modernization and progress:

1) Encounter with the Jewish culture caused degradation in the family and tribal structure; thus, the social base lost its prior stability and the tribal framework lost its importance.

2) The new environment was unsuitable for raising and grazing animals; and usage of money increased. Most of the Bedouin had to look for paying jobs and acquire new types of professions.

3) The law of compulsory education revolutionized the Bedouin society that never before had been obliged to send its children to school.

These extreme changes and others brought the Bedouin society closer to other segments of the Israeli society and to sharing some of the problems characterizing it; however, they were less equipped to cope with the problems their tradition did not provide for" (Al-Aatzm, 1983).

“...nevertheless, the Bedouin population did not undergo a complete transformation; it underwent change, while it carried the past remnants within. The past patterns no longer fit the conditions it thrived to adopt; some of 
them acted as impediments, preventing solutions based on the values of modern society. The remaining patterns and the residues of behavioral and moral tradition established during several generations were not easy to change" (Abu-Rabia-Queder \& Weiner-Levy, 2008; Al-Aatzm, 1983).

"The transformation of the Bedouin society created conflicts between tradition and progress. The abandoning of animal growing as the main income source and turning to seek employment created a new reality, combining tradition and culture with the modern era. The change caused distress in most aspects of life" (Ben Rabi, Amiel, Najm, \& Dolev, 2009).

\subsection{Characteristics of the Bedouin Society}

"The Bedouin family is more an extended family than a nuclear family, as in most cases it is composed of a husband, wife, grandparents, and in several cases there are also the second wife, the third wife, and the fourth and in consequence several children. Polygamy, which was a common phenomenon in many societies in the past, is still a conventional norm and a central social institution in the Bedouin culture bound to the patriarchal social structure, and the structure is significant to the group and the tribe" (Al-Krenawi, 2003).

"Polygamy, as a normative social structure, is anchored in the faith of Islam, which allows a man to marry four wives in certain conditions. It may create a social problem, as the man is required to sacrifice his wealth. Polygamy is a mark of high social status and wealth reflected in the Bedouin statement: "Izz al-a' yla blmal wbl rjal," meaning: The prestige of the family is in the capital and men. In the past, polygamy was a characteristic feature of tribal chiefs; today it characterizes people of high income, who perceive multi-marriage an investment in offspring as well as an expression of their economic success" (Ibid.).

Generally, if a married man has many sisters he may choose to take another wife to prevent his sisters having a lengthy spinsterhood. Thus, he agrees with another man to perform an exchange marriage (Badal): they each marry a sister of the other and no dowry has to be paid.

\subsection{The Education System and Its Significant Role in the Transformation Processes of the Bedouin Society}

"The significant socioeconomic processes that occurred among the Israeli Bedouin due to urbanization and permanent settling played a major role in the development of the Bedouin educational system, forcing them to gradually abandon some of their old ways and adopt new ones. Implementation of the compulsory education law, in 1953, caused a change in the educational perceptions of the Bedouin society. Formal education and the acquisition of western type education began to receive priority in various social relations and preferences. This changing process caused a radical difficult and complex social change in Bedouin society "(Meir \& Barnea, 1988).

\subsubsection{Aspects in the Development of the Israeli Bedouin Educational System}

The Israeli National Educational System had been organized and consolidated in 1953, after the Knesset (local parliament) issued the state law of compulsory education. Since its establishment, the educational system strove to provide education and educational services to all the children in Israel, of all the various segments of the state's population. From the start, the administration encountered problems regarding the promotion and implementation of the educational system for the Bedouin population, as the Bedouins opposed application of western education norms. These difficulties convinced the Ministry of Education that there was a need to build a special separate educational system for the Negev they invested time and efforts to convince parents, local sheiks and other community leaders. These efforts led to the creation of local educational committees, headed by local sheikhs; the ministry also conducted an information campaign, regarding the importance of education, among parents. These obstacles delayed the final implementation of compulsory education among the Negev Bedouin population until 1970.

Unlike the situation in the south, the educational system for Bedouins in northern Israel was an integral part of the general inclusive state educational system designed for the Israeli-Arab population. However, in time, especially in the last two decades, the Bedouin educational system has been separated from the Arab educational system and today it has become a semi-independent section led by Dr. Muhammad el Heib, an educator from the village of Tuba-Zangaria. The change came from the need to preserve the Bedouin uniqueness, especially the heritage aspect, and to improve the system in order to find solutions to its specific unique problems.

The relatively impressive achievements of the Bedouin educational system in recent years, especially in the last two decades, cannot be ignored. This system has managed to raise a generation of accomplished scholars in almost all the areas, some of whom fulfill key roles in both public and private sectors.

Another impressive achievement has occurred in women's education. To date, almost all Bedouin girls are high 
school graduates and a significant percentage of them choose to continue and attend higher education. Although the women's representation in the advanced academic degrees is still scanty, it is constantly growing. Today, approximately $95 \%$ of the young Bedouin generations are literate, and at least $90 \%$ of them have completed high school (Rudnitzky, 2011).

According to Khawaledi (2000), the Bedouin educational system suffers difficulties, deriving from contradictions between traditional values and social values ingrained in the educational program, along with the conduct and organization of schools in the state of Israel. The values that are most important to Bedouins are honor and freedom. The Bedouins bestow an important value to freedom; the freedom to move in the vast borderless desert without being tied to a particular piece of land or a specific house, and the freedom that enables a man to choose how much to invest in his work. The second important value is honor; which is comprised of the general honor affected by a person's behavior, the courtesy shown to the surrounding social circle, and the respect given to a woman (Ginat, 1987, 2000).

\subsection{The Status of the Bedouin Woman}

The Bedouin population has its own tradition regarding the rules of the relationship between a man and his wife and his children. These rules determine the patriarchal nature of the Bedouin society, in which the man has an absolute undisputed authority making him the master of the family, while the roles of the wife and the children are to serve him obediently.

"The Bedouin's traditional custom demands close protection of the family honor, and it severely punishes anyone who dares to breach these laws. As the father is an absolute master of his family, no one has the authority to intervene between the man and his family members whom he treats as he chooses. The Bedouin perceives a woman as "worthless", but on the other hand, he keeps her and protects her as if she was "precious", allowing no one except relatives near her" (Ashkenazi, 2000).

"Inside the house/tent the wife is separated from everyone; there is a role division and this division distances their mutual emotional life. Contacts with the external world are conducted by the husband, in most cases the wife does not and is not expected to make decisions or express an opinion. The Bedouin man excels in his strength and endurance; he is usually easy going and contented. He will rather not work in physically demanding labor; as he perceives such a job as exhausting his power and that doing it prevents him from doing what he was born to do. The significant changes that have occurred in the social, political, and economic aspects have led to a significant change in the status of the Bedouin woman" (Pasta-Schubert, 2005).

"The transition of the Israeli Bedouin population from nomadic lifestyle to permanent settlements and the ensuing improvement in their life quality has brought a significant critical improvement in the status of women. When the Bedouins lived in tents, the role division was clear: the woman was responsible for the land, tending the flock, taking them to grazing grounds, bringing water, cooking, and looking after the children. Thus, the feminine identity was bound to her way of life. The transition to an urban lifestyle has affected her life and her roles" (Abu-Rabia, 2001).

This significant change derives from a number of reasons-the most important one is tied to the law of the democratic state, which is based upon equal opportunities, especially regarding education and welfare, as citizens are not distinguished by gender.

\subsection{Adolescence}

\subsubsection{Adolescent Characteristics}

According to Saruf, Cooper, and Dahart (1998), the adolescence phase starts approximately at the age of 12 years. This phase is characterized by mental and physical development and it is considered a transitory phase between childhood and adulthood. The adolescent becomes an autonomous person, he acquires a new stand in the family, as also new self-awareness that helps him/her to become conscious of his/her difficulties and is encouraged to seek help, while public self-awareness might delay help-seeking .

The main characteristic of this age is the significance of the age group and the increasing demands for independence, leading to confrontations with the parents. "The adolescents find support in their peer group ,which often leads to the creation of an adolescent sub-culture, which dictates a similar dress code, language, music preference, and so on" (Ziv, 1993).

“...With maturation and puberty the interest in the opposite gender increases and the social interaction becomes of a heterosexual nature. In this phase of life, the individual also begins to plan the choice of a profession, a factor that might determine to a certain extent the individual's future social status as an adult" (Peri-Piamenta, 
1999)

\subsubsection{Adolescence in the Arabic Society}

Arabic youth comprise of $15.3 \%$ of the Israeli Arab society, making it a considerable component of this society. The Arabic society in Israel experiences a complex process of social and cultural changes causing a crisis that shakes its important value system. Circumstances place the young generation is the center of these changes. One of the signs of this crisis is the value polarization that characterizes this society: there are people who preserve traditional norms and do not adapt to the modern values, and on the other end, there are educated professionals that choose to adopt the individualistic approach for themselves and their environment.

Rekhess and Rudnitzky (2008), claim that this inner polarization creates an acute internal conflict, specifically in the young generation.

"The self-image of Arab youth in a society defined as collective is shaped on the basis of the social-cultural commands: the individual does not perceive himself as an independent entity, but as a collective personality subject the support of social emotional favors" (Dwairy, 1997, 2001).

"The ethnic origin has a dual effect on the adolescents from minority group compared to adolescents from majority group. One of the explanations is that adolescents from minority groups derive power from the ties they have in their reference group to regulate the negative influence on the self-image. The differences between Jewish and Arab adolescents are linked to the social change that occurs in the Arab and Druze society. The differences are reflected in the family values and education; they raise questions and may encourage educational intervention that is aimed at elevating the education level of the family. This issue has been found to be very important among Arab male adolescents and among Druze female adolescents. Among the changes, the transition to the pursuit of academic education is immediate and direct" (Sginer, 2001).

According to Abu-Asbah (2005), the exposure of Arabic youth in Israel to western culture is higher than that of Arab youth in the neighboring countries. This exposure occurs due to direct contact with the Jewish majority group, and the indirect western culture impact transmitted by the media, including increased surfing on the Internet. This exposure creates a crisis between generations, raising value dilemmas relating to modernity, such as dress code, time orientation, the individual's status in the family, the attitude toward religion, the parent-children relationship, family solidarity, and the like, within the collective Arab group.

\subsubsection{Adolescent Phase among Girls}

Sexual development differs between the two genders; girls begin to develop approximately two years earlier than boys. These changes might affect the social aspects of the female adolescent. It can also affect her social status among her peers and in the eyes of the opposite sex.

\subsubsection{Girls' Adolescent Phase in the Bedouin Society}

"External expression of sexuality is perceived as immodest and dishonoring; thus, in order to prevent unnecessary social tensions conservative societies have believed that the best way would be to prevent any contact with the other gender and separate them in status and roles" (Al-Krenawi, 2000).

Traditional education has aimed to prevent the girls from "bringing shame on the family" $\left(A^{\prime} r d\right)$. The Bedouin explains that he can remove any stain of shame except the stain of "A'rd" which stays forever.

Girls have a lower social status than boys, as men felt sexually threatened by women. Therefore, society chose to impose limitations on them, as they were perceived as a source of temptation (The holy Quran, Chapter 12, $24^{\text {th }}$ v').

"The Bedouin women denied the rights to protect the family honor. Bedouin female teenagers are not allowed to leave their home by themselves; they must always be accompanied by their mother or brother. Girls who have completed their schooling spend most of their time at home and help their mother in household tasks" (Abu-Rabia, 2001)

\subsection{Mothers'-Daughter's Relations}

In most societies the bond between mothers and daughters is characterized to be closer than the bond between mothers and sons. A psychoanalytic theory explains that the essential characteristics of the bond between mother and daughter are the fact that the personality of the daughter is consolidated during the years alongside the same person, which is her mother, while the personality of the son's identification model changes. The continuity of the mother-daughter bond strengthens it, but it also cause a blurring of the borders of the mother's ego and creates difficulties in the separation process (Lamdan, 2004). 
During the phase of adolescence, daughters tend to relate negatively to their mothers, but during the stages of marriage, pregnancy, and child birth, they tend to renew the bond and the closeness.

In the Bedouin society there is a distinction between sons and daughters which is affecting the relations between the girl and her mother. Tradition dictates that the daughter stays home under the supervision of her mother.

"When a son is born, his father is considered blessed, as he will provide for the family in the future. Therefore, mothers invest time and attention on their sons, while the daughter receives a satisfactory status only when she marries and bears children" (Zba, 1992).

Thus, the birth of a daughter is not a joyful occasion, and the mother hurries to get pregnant again in the hope of having the son who will support the family in the future. Thus, the son is always the preferable child and a girl learns of her secondary place and lower social status from an early age. On the other hand, the mother keeps the daughter close to her, and guards her, so she enjoys her and identifies with her. Thus, when the girls reach adolescence, the mothers experience an inner conflict between allowing them freedom and independence and continuing the closeness, giving, and protection.

"From the age of 10 years, the Bedouin female adolescent behaves like an adult; she hides her face from men and covers her face with a veil when she exits the home" (Al-Krenawi, 2000).

\section{Methodology}

\subsection{Research Questions}

1) What are the patterns of the mothers' intervention in the education of their adolescent daughters?

2) What is the connection between the mother's intervention in her daughter's education today and her own experience of that age in the past?

\subsection{Research Method}

This study was conducted in a qualitative approach, which is often used in behavioral studies. It deals with quality subjective information, and its interpretation is based on the thoughts and feelings of the researcher. According to Shkedi (2003), in most cases, a qualitative study seeks new explanations to existing materials. A study of this category can investigate traditions, behaviors or the lifestyle of the studied population.

"A qualitative study draws its data by investigating them or builds a theory on the basis of the information gathered. The researcher is part of the study and he uses his abilities to reach comprehensive insights. This research method enables the participants to reflect reality and present an interpretation of that reality" (Tzabar-ben-Joshua, 1990).

\subsection{Research Tool}

The research tool chosen for this study was an open semi-structured interview. The objective was to enable the interviewees to describe their perceptions and to voice their opinions on the research questions. The semi-structured interview included a number of pre-set questions, but it allowed flexibility and presentation of additional questions, if the content of the interview opened the door. The framework of the interview enabled a description of experiences, narration of stories and anecdotes, and a reference to remarks and opinions of people within the studied environment, with regard to other people who shared the same environment. Most scholars proposed that this tool enjoyed most of the advantages of the pre-constructed interview and an open interview.

\subsection{Research Population}

The research population of this study comprised six Bedouin mothers of teenage girls from Bedouin villages in Galilee, in northern Israel, with age ranging from the mid-thirties to forties. All the participants but one were professional working mothers: a teacher, a school counsellor, a kindergarten teacher, a cosmetician, a child care person, and one housewife. Four of the six had one adolescent daughter and two of them have two teenage daughters. The names used in this study are not the participant's actual names, as anonymity was a mutually agreed pre-condition.

\section{Data Analysis}

The data gathered was arranged according to categories and their relevancy to the research questions to enable analysis of the results. The findings revealed various patterns of the mothers' intervention in the education of their adolescent daughters. It seems that there is a tendency to make some limited change in the recognition of the social development; nevertheless, there is a remarkable preservation of the conventional Bedouin tradition. The answers received in the interviewees provide the following categories: 
A. The perception of the Bedouin woman in the Bedouin society

B. The characteristics of the relations: consideration and areas of intervention of Bedouin mothers in the affairs and behavior of their daughters.

C. The present patterns of mothers' intervention in the affairs of their adolescent daughters

D. The mothers' coping with modernism and the measure of new directions in the Bedouin society compared to the previous period.

A. The perception of the Bedouin woman in the Bedouin society

\section{A.1 Bedouin woman's self-perception}

The interviews conducted with the participants indicated that the modern Bedouin woman tends to preserve and follow the traditional value system of the Bedouin society, especially with regard to their roles in the family, since she believes that keeping the tradition and manners will keep the family together.

\section{Quotations:}

"I am conservative, I care for the traditional manners; I am a woman and my role is to raise my children, look after them, and preserve the customary manners" (A'watif).

Variations of this answer had been received from other participants. They appear to be more convincing than the following statement:

"I am a woman like all other women, educated and understanding. I am a Bedouin. I am proud of my values, my culture, and my heritage" (Lutfia).

One of the interviewees, (Fawzia) although claiming to be a free agent, expresses consideration to her surrounding society:

"I am a free woman. I respect traditional values and the society I live in."

The same emphasis was stated by another participant in this version:

"I am an educated woman. I go out and I have a status in my society, but I am also a Bedouin woman who follows traditional customs. I consider myself a conservative" (Samya).

Therefore, although most of the interviewees are educated, they still perceive themselves as conservative and choose not to deviate from the traditional Bedouin cultural norms.

\section{A.2 A perception of the Bedouin society and a Bedouin woman's characteristics}

According to the interviewees, the Bedouin woman is characterized by acceptance of her different social status, the general view that her place is mainly inside her home, raising her children. She submits to the traditional social authority regarding the honor of the husband's family and the surrounding society. However, there are signs that the status of the Bedouin woman is beginning to change, due to her education and her entering the work market. The following extracts reflect these findings:

A "Bedouin woman is characterized by the respect she shows to people, and to her family; she will not bring shame to her family and the society" (Fawzia).

A "Bedouin woman symbolizes the honor of the man. She is a woman who cares for her society and the environment she lives in" (Samya).

"She oversees the children's education. Especially girls' education, because that is what she is required and expected to do, to look after the education and the house: to clean, cook, and put things in order so that everything will look good" (Tamam).

"A Bedouin woman does not give herself a place in society because she is prevented from getting it, regardless of the change. Compared to the past, nowadays she gets education and makes decisions regarding her own affairs, but she still lives with boundaries and restraints" (A'watif).

"Due to the transformation the society undergoes, a woman of the Bedouin population is' like any other woman in the Israeli society. She is working, learning, raising children; she is also educated, fashionable, pampered, and so on. All the above have occurred due to the social transformation" (Manar).

These last expressions of the interviewees suggest an awareness of the change and orientation toward change in the woman's social status.

B. Characteristics of the relations between Bedouin mothers and their daughters: 
All study participants claim that the relationship between mothers and daughters is based on mutual understanding and respect. There is a tendency to stress the point that such relations occur within the boundaries of the conservative society, but there is also reference to the elevation of the daughter's awareness to the social rules of the surrounding society. Some participants claim that sometimes a mother can develop ties of friendship with her daughter. The following are extracts regarding these issues:

"The relationship is very conservative. I am her mother and I treat her as a mother, no more and no less. I keep the boundaries between us to ensure that she will be well-educated according to the rules and regulations of the others and the environment" (Fawzia).

The same approach was conveyed by other interviewees. Others point out that the mother's and others instructions represent more tolerance and suggest a friendship tie:

"The relationship between me and my daughter is based on mutuality; I try to be a good mother and give her everything; we sometimes treat each other like friends that speak openly. She is very open and we are very close because she is always with me." (A'watif).

C. The mothers' listening and consideration

The study participants declared that their daughters receive what they need and what they ask for within the conventional boundaries of the Bedouin society's conception regarding the needs of adolescent girls.

'...I am very careful with her because sometimes her wishes and choices are irrational so I have to help her to choose" (Manar).

"...There are things that I do not give her because I think they are inappropriate; for example, a cell phone or participation in journeys or taking a walk about" (Fawzia).

"I always listen to her. Our relationship is developing daily. I listen to her wishes and explain to her where it might lead to. If they may lead to negative consequences I explain that to her, and make sure that she understands" (Samya).

All the participants claim that they listen with empathy, but they are very strict if their daughters' wishes do not tally with their perception of what is appropriate for them.

D. Mothers' intervention in their daughters' affairs in current era.

\section{D.1 Boundaries of freedom and mother's intervention in the life of the adolescent daughter}

The mothers explain that they give their daughters freedom and responsibilities at home, they also refer to guidance and parental authority for anything concerning a group or behavior outside. Their intervention is perceived as their right to teach good manners and warn their child about unacceptable behavior. The following statement points out an intervention derived from the rules of the Bedouin family, as expected and required by social tradition:

"I allocate responsibility to a point, but there are instances in which I interfere; as a Bedouin woman, the responsibility of raising my daughter appropriately is on me, as part of our honor. So I always intervene in every aspect, in the way she dresses, in the way she talks..." (A'watif).

Another participant is more specific:

"I give her space, but only at home, do I let her take responsibility for herself; I pamper her if she chooses, I let her be responsible for herself when she goes to school. I interfere only in sensitive places, like when she wants to get close to somebody in her class, or when she overdoes self-pampering and goes to school inappropriately dressed or uses makeup" (Fawzia).

"I allot her very limited responsibility. I intervene almost in everything because at this age she is not fully aware of right and wrong and as her mother I have to supervise her education as it is my job" (Lutfia).

The mother's intervention in the daughter's education is also reflected by the mother teaching her daughter about the Bedouin family good reputation:

"She shows me that she is growing up and that she assumes responsibility in certain areas; so I show her that I trust her and I no longer treat her as a child. I listen to her, and give her space. I interfere only where I feel that I should and have the right to do so, because if I will not interfere, people will say that her mother did not educate her as she should have. They will not even mention her father" (Samya).

D.2 Bedouin mothers' perception of their intervention in their daughters' affairs:

An actual mother's intervention is conveyed by explaining, instructing, and setting borders, which adolescent 
girls should consider; due to the fact that from a social and behavioral aspect, they are in a transitory phase and they ought to and are expected to obey traditional rules and social conventions.

"I constantly intervene, I talk to her, and I explain that I have to know everything and I intervene because she is still young and the mother must be alert to her daughter's behavior" (A'watif).

"My intervention derives mainly from my experience as an adolescent in the Bedouin society. I intervene because I know better, I have more experience, and mostly because I know what is allowed and what is forbidden according to Bedouin tradition" (Samya).

"I define my intervention as frequent; it derives from being anxious that she will pass the adolescent phase in an appropriate manner" (Lutfia).

The other interviewees conveyed the same ideas. They intervene because they know better, or because they have to make sure of the daughter's "correct" behavior.

\section{D.3 Mothers' intervention factors}

Bedouin mothers' intervene in the education of their daughters due to a number of reasons.

1) In a Bedouin society the daughter's behavior is directly attributed to the mother and the way she raised her, since according to the Bedouin social structure, the mother is the sole person responsible for the education of the female children. Thus, if the girl behaves appropriately, it means that the mother has done a good job and vice versa.

2) Another factor affecting the issue is the overexposure of the young generation to the media and communication technology, a factor powerful enough to cause deviation from the conventional norms of the traditional Bedouin society, which could lead to social chaos and a reality unacceptable to the Bedouin society.

3) The third driving factor relates to disastrous consequences that might cause the emergence of a reality in which the Bedouin society will adopt behavioral patterns that are different, unconventional, and unacceptable to the cultural traditional Bedouin heritage.

The study participants emphasize that the reasons they intervene in their daughters' education are mostly influenced by the expectations of the surrounding society:

"I am afraid to lose her at this age, which will not be good for both of us, since in our society they blame only the mothers" (Tamam).

"The advanced technology, exposure to social networks, Facebook and cellular phones- I feel that the implications of the technological era creates a distance between me and the children" (A'watif).

E. The areas in which mothers intervene in their daughters' affairs

E.1 Areas of intervention in the eyes of the mothers

The areas of intervention seem to mainly relate to social aspects, such as, the girls their daughters befriend, limitation on the usage of social networks, the dress code and general appearance. The mothers also report about their intervention in school matters and the academic achievements of their daughters, as they emphasize the need for their daughters to reach a respectable status. The following are some extracts from the interviews:

"I interfere mostly in her affair out of home, the choice of friends, and personal talks with friends" (Tamam).

"I do not allow her to speak on the phone in the privacy of her room; she can talk freely in my presence. I also intervene in her clothes; I make sure that she wears modest clothes appropriate to the place and the society" (Samya).

"I intervene mostly in the academic area because I want my daughter to achieve a respectable social status. I also intervene in her social affairs and the clothes she wears. I also intervene emotionally I listen to her feelings and advise her regarding what is allowed and what isn't" (Lutfia).

\section{E.2 Intervention in choosing friends}

The mothers interfere in their daughters' choice of friends. The main factor is the family background of the girlfriend. Friendship with male youngsters is absolutely out of the question. They all stress the fact that social ties with boys are not allowed.

"I always ask about their background, what family they come from. I do not allow male friends, only as brothers" (Fawzia).

"I do not interfere but it is important for me who her friends are. Male friends she can treat only as brothers. I 
explain to her that at this age there is no real love, and she is not allowed to fall in love at this age, because such a relationship might threaten our family socially, therefore, it is forbidden" (A'watif).

The other answers were more or less along the same lines.

\section{E.3 Permission to exit the house}

All the mothers negate the possibility that the daughter will leave the house without their permission. They ensure that a decision regarding this issue will always be theirs, including the time table (when they can leave and when they must return).

"I determine the exact hour she can leave for the event and the hour she has to come home" (Lutfia).

"I determine the hours she goes and comes back. She is not allowed to be out in the evening" (Samya).

F. Trends of change in the Bedouin society compared to the previous era, and the manner in which Bedouin mothers cope

\section{F.1 The change in Bedouin mothers' intervention between the previous and the present era}

The general impression is that at present the Bedouin mothers tend to intervene in their daughters affairs more than they did it in the past. It seems that the mothers today are more open to listening to their daughters, but they also find more ground for intervention. They are aware of the changes occurring within the Bedouin society, and they are anxious to be there and safeguard their daughters. They also remember and sometimes apply the measures their mothers used when they were adolescents.

"We also intervene, just like my mother did, so our daughters will be raised according to our social norms" (Tamam).

"There is a difference, when we were teenagers, our mother did not let us breathe; she interfered in everything. She made all the decisions for us. She never listened; her only concern was how her daughters will be perceived in the society. She wanted people to point her out and declare that she raised her daughters successfully. Today the intervention derives from care and concern to adapt to the ongoing social transformation and develop, but at the same time to preserve our tradition" (Samya).

One of the participants hints at the impact of technology on the trend of the change in attitude:

"My mother did not just intervene, she never let us pamper ourselves or go out. Of' course I intervene because I want to raise my adolescent daughter's awareness, but I do give her breathing space sometimes" (A'watif).

"My mother simply cut in, she did not explain, but I do, I explain every detail of anything. This quickly developing era makes it necessary for me to do so, otherwise I might lose control" (Lutfia).

F.2 Coping with the tendency for rebellion and the adolescent daughters' lack of awareness

Mothers of adolescents face many difficulties they have to cope with, such as rebellion and a tendency to disobey. Bedouin mothers are willing to take harsh measures and punish the girls for obstinate demands that do not meet the social norms and conventions. The mothers perceive adolescents as immature persons, who lack the understanding of the importance of traditional values. They believe that adolescents are in dire need of adult guidance and supervision.

"This age group is not fully aware of what's happening, also, they do not respect the place they are in, they do not respect values and tradition. I explain to her so she will understand what it is all about" (Tamam).

"I try to be patient and positive; I explain to her about the culture, what is allowed and what is not, because she has no awareness; since all of them are mentally and emotionally immature." (Lutfia).

"Rebellion in this age appears powerful, so I try to cope. Sometimes I refuse to give her what she wants and I do not listen, like a sort of punishment. In our society a daughter's rebellion can lead to murder if she reaches places she is not supposed to be in" (Samya).

Intervention aimed to raise the daughter's self-awareness:

"Sometimes our conversation reaches a dead end, so I leave it for a while to calm things down. Later I renew the conversation and explain to her that there are things she cannot get and that she has to learn the norms and the consequences of not following them: I use examples of everyday life to make her understand" (A'watif).

F.3 Three obstacles that bar the development of Bedouin female adolescents

The study participants have different views regarding this issue; some believe that tradition and value do not bar the adolescent girl from personal and social development, while others voice the opinion that certain customs 
and traditions do indeed bar the personal development and social integration of the adolescent girl.

"Today there are several women who go to learn or work outside, but they all keep the honor and their social status; keeping the values and tradition are not necessarily preventive factors barring the development of the adolescent girl" (Tamam).

"The Bedouin society underwent transformation; keeping values and tradition does not mean that the woman is barred. The Bedouin woman got out of the house, learned, and underwent a certain status change, but she keeps her honor, and the honor and respect of the society" (Samya).

"Every society changes with time; the Bedouin society is still conservative, but it is does not bar women... a person who respects the culture can also progress" (Lutfia).

Others think that the woman's change of status requires a different social perspective:

"The customs and traditions are still considered obligatory and women submit to dictates. These norms do not allow the adolescent girl to realize her full potential" (Manar).

Other participants were of the opinion that the woman's social status is still highly restricted.

The findings indicate that the Bedouin women of today had bettered their social status compared to their mothers, but there is still a lot to be desired. Most women are conservative and bound to the cultural customs and tradition. They accept their allotted place in society, and they train and educate their daughters according to these traditional values. The mothers allow their daughters freedom and some responsibility within the house, but they are very protective with regard to the company that they keep and are very authoritative with regard to their behavior and conduct outside the house.

Their intervention in their daughters' daily life is considered a fundamental right and duty, but unlike their mothers' conventional behavior in the past, the Bedouin mothers today are more open minded, they listen and are willing to discuss and explain. They supervise the affairs of their adolescent daughters, but they also encourage them to invest in school and develop as individual persons.

\section{Discussion}

This study aimed to examine the areas of Bedouin mothers' intervention in the educational affairs of their adolescent daughters, and to verify the difference between the Bedouin mothers today, compared to their experience and their memories of their mother's intervention in their affairs when they were adolescents. The finding showed that although Bedouin women today are more educated and many of them have joined the labor market and contribute to the family's income, their self-perception of their role in Bedouin society is very similar to that of their mothers, who accepted the patriarchal social structure and the traditional role of the woman in this society.

However, the findings also show that the mother-daughter relation has changed; the mothers today are more open minded and see the daughter as a person. They want her to succeed in school, to learn and progress, but on the other hand, they fear that too much freedom may lead to an undesirable path, so they are very strict and protective. The girls can enjoy relative freedom in the house, but their company is supervised and their behavior outside has to fit the rules and customs, since from a social point of view, the girl is not considered as a unique individual, but rather a part of a larger social unit, where she is obliged to follow rules and keep a certain status. She cannot breach norms and tradition in order to adapt to external behavioral patterns.

The modern Bedouin mothers recognize the fact that in this day and age, exposure of the adolescent daughter to other social segments and the media are unavoidable, so they set rules for the girls and invest in guidance and supervision. Encountering new cultural values creates new dilemmas for Bedouin women; therefore, they strive to balance their wishes in order to realize some of their personal autonomous choices and their restrictive cultural norms and expectations.

\section{Summary}

This study which is a pilot study conducted in this particular population, was almost a case study, and should be treated as such, since the participants were all Galilee Bedouin mothers of the same age group, and most of them were employed in education-related positions. Thus it has given us a glimpse into an unchartered social field. As the issue is wider and far more complex, future studies might give us a better understanding of the Arab women transformation in changing times.

\section{References}

Abu-Asaba, K. (2005). The Arab Education System in Israel: Development over the Years and a Current 
Situation Report. In A. Heider (Ed.), The Book of Arab Society in Israel (pp. 201-221). Jerusalem: Van-Leer Institute, Hakibbutz Hameuhad Publications (in Hebrew).

Abu-Rabia, A. (2001). A Bedouin Century: Education and Development among the Negev Tribes in the 20th century. New York and Oxford: Berghahn.

Abu-Rabia-Queder, S., \& Weiner-Levy, N. (2008). Identity and gender in cultural transitions: Returning home from higher education as 'internal immigration' among Bedouin and Druze women in Israel. Social Identities, 14(6), 665-682.

Al-Aasam, S. (1983). The Social Services in the Bedouin Sector in the Negev what there is and what is lacking. Notes on the Subject of Bedouins, 14, $72-81$ (in Hebrew).

Al-Krenawi, A. (2000). Ethno-Psychiatry in the Bedouin Arab Society in the Negev. Tel- Aviv: Hakibbutz Hameuhad Publications (in Hebrew).

Al-Haj, M. (1987). Social Change and Family Processes: Arab Communities in Shefaram. Brown University studies in population and development. Boulder: Westview Press.

Al-Krenawi, A. (2003). Bedouin-Arab families in the Middle East. In J. J. Ponzette (Ed.), International Encyclopedia of Marriage and Family Relationships (2nd ed., Vol. 1: Ab-Du). Macmillan Reference USA.

Ashkenazi, T. (2000). The Bedouins in the Land of Israel. Jerusalem: Ariel (in Hebrew).

Barakat, H. (1985). The Arab family and challenge of social transformation. In E. W. Fernea (Ed.), Women and the family in the Middle East: New voices of change (pp. 27-48). Austin: University of Texas press.

Ben Rabi, D., Amiel, S., Najm, F., \& Dolev, T. (2009). Children in the Bedouin Population in the Negev: Characteristics, Needs and Patterns of Use of Services. Jerusalem: Mayers-Joint-Brookdale Institute (in Hebrew).

Cohen, M. (1999). The Status of the Bedouin Woman in Israel. Economic and Social Changes. Vision and Practice in Ahva College, 5, 229-239 (in Hebrew).

Dwairy, M. (1997). A biopsychosocial model of metaphor therapy with holistic cultures. Clinical Psychology Review, 17(7), 719-732.

Dwairy, M. (2001). Foundations of a psycho-social dynamic personality theory of collective people. Clinical Psychology Review, 22, 1-18.

Dwairy, M., Achoui, M., Abouserie, R., Farah, A., Ghazal, I., Fayad, M., \& Khan, H. (2006). Parenting styles in the Arab societies: A first cross-regional research study. Journal of Cross-Cultural Psychology, 37(3), 230-247.

Garcia, F., \& Gracia, E. (2009). Is always authoritative the optimum parenting style? Evidence from Spanish families. Adolescence, 44(173), 101-131.

Ginat, J. (1987). Blood Disputes among Bedouin and Rural Arabs in Israel: Revenge, Mediation, Outcast and Family Honor. Pittsburgh: University of Pittsburgh Press in cooperation with Jerusalem Institute for Israel Studies.

Ginat, J. (2000). Vendetta Ostracism Mediation and Family Honor. Haifa University: Zamora Bitan (in Hebrew).

Hassan, M. (1999). Patriarchy, the State and Murder for Family Honor. Within: Dafna Yizraeli and others. Sex Gender Politics (pp. 267-305). Tel Aviv: Kav Adom, Hakibbutz Hameuhad (in Hebrew).

Kelly- Laine, K. (1998). Parents as Partners in Schooling: The Current State Affairs. Childhood Education, 74(6), 144-149.

Khawaledi, S. (2000). Blood Disputes and the Ways of settling them according to the Customs of the Sharia and the Laws of the State: Transformations and changes among Bedouins and villagers in the Galilee. Notes on the Subject of the Bedouins, 32, 51-62.

Lamdan, A. (2004). From Silence to Shout to Speech: Three Generations of Mothers in a Kibbutz. Ramat Efal: Yad Tabenkin Publications (in Hebrew).

Meir, A., \& Barnea, D. (1988). Spatial Aspects and Structural Changes in the Bedouin Education System in the Negev. In I. Eini, \& A. Gurion (Eds.), The Bedouins notes and articles. Sde Boker College: Ben Gurion University, The Society for the Protection of Nature (in Hebrew).

Pasta-Schubert, A. (2005). I Go out and Really Feel the World, I See the Things more Clearly: Women, Higher 
Education and Bedouin Society in the Negev. Megamot, 4, 659-681 (in Hebrew).

Peri-Piamenta, A. (1999). Spoken Psychology: Concepts in Psychology of Daily Life. Tel Aviv: Modan.

Reches, E., \& Rudnitsky, A. (2008). An Arab Boy in Israel-between Chance and Risk. Tel-Aviv: Tel-Aviv University, the Dayan Center and the Conrad Adenauer Fund (in Hebrew).

Rudnitzky, A. (2011). Bedouin Society in the Negev: Social, Demographic and Economic Characteristics. Neve Ilan: Initiative of Keren Avraham (in Hebrew).

Saruf, A., Cooper, R., \& Dehart, G. (1998). Development of the Child its Nature and Course. Tel- Aviv, the Open University (in Hebrew).

Sginer, R. (2001). Youth in Israel Make their Way to Adulthood: Orientation Future of Arabs and Druze by Comparison to Jews. Megamot, 1-2, 113-114 (in Hebrew).

Shkedi, A. (2003). Words Trying to Touch: Qualitative Research-Theory and Implementation. Tel Aviv: Ramot (in Hebrew).

The holy Quran.

Tzabar-ben-Yehoshua, N. (1990). Qualitative Research in Teaching and Learning. Ramat Gan. Masada (in Hebrew).

Zba, R. (1992). The Place of the Cradle in Education for Values. Hed Hahinukh, 2, 17-19 (in Hebrew).

Ziv, A. (1993). Psychology: The Science of Understanding the Human. Tel Aviv: Am Oved (in Hebrew).

\section{Copyrights}

Copyright for this article is retained by the author(s), with first publication rights granted to the journal.

This is an open-access article distributed under the terms and conditions of the Creative Commons Attribution license (http://creativecommons.org/licenses/by/3.0/). 